\title{
Chronic Therapy with Nipradilol, a $\beta$-Adrenergic Blocker, Attenuated Left Ventricular Remodeling Following Myocardial Infarction in Rats
}

\author{
Hiroyuki Sonoki ${ }^{1}$, Masaki Nakamura ${ }^{1}$ and Akira Takeshita ${ }^{2}$ \\ 'Tokyo Research Laboratories, Kowa Co., Ltd., 2-17-43 Noguchi-cho, Higashimurayama, Tokyo 189, Japan \\ ${ }^{2}$ Research Institute of Angiocardiology and Cardiovascular Clinic, Faculty of Medicine, Kyushu University, \\ 3-1-1 Maidashi, Higashi-ku, Fukuoka 812, Japan
}

Received July 26, 1996 Accepted March 18, 1997

\begin{abstract}
We determined whether chronic treatment with nipradilol, a $\beta$-blocker with vasodilating action, reduces left ventricular cavity dilation (LV remodeling) following myocardial infarction and improves cardiac performance. Myocardial infarction was produced by coronary artery ligation in 16-week-old female rats and then the rats were treated for 3-4 months with nipradilol $(10 \mathrm{mg} / \mathrm{kg} / \mathrm{day})$ or vehicle $(0.5 \%$ carboxymethylcellulose). The effect of nipradilol on LV remodeling was evaluated by assessing the left ventricular end-diastolic volume index (LVEDVI) and passive pressure-volume relation curve. Since LVEDVI depends on the infarct size, LVEDVI was compared between the vehicle- and nipradilol-treated rats with similar infarct size (10-40\%). At 3-4 months after myocardial infarct production, the left ventricular end-diastolic volume index in the vehicle-treated rats with myocardial infarction was significantly increased, compared with that in the sham-operated rats without infarction. The nipradilol-treated rats had a significantly smaller left ventricular volume index than the vehicle-treated rats $(2.04 \pm 0.16 \mathrm{ml} / \mathrm{kg}$ in the vehicle-treated group vs $1.36 \pm 0.10 \mathrm{ml} / \mathrm{kg}$ in the nipradilol-treated group, $\mathrm{P}<0.01$ ). The maximum cardiac index achieved by volume loading as an index of cardiac performance was significantly greater in the nipradilol group than the vehicle group $(254.5 \pm 12.6 \mathrm{ml} / \mathrm{min} \mathrm{kg}$ in the vehicle group ys $347.9 \pm 20.2 \mathrm{ml} / \mathrm{min}$ $\mathrm{kg}$ in the nipradilol group, $\mathrm{P}<0.01$ ). These results suggest that chronic treatment of nipradilol attenuated left ventricular cavity dilation after myocardial infarction and improved cardiac performance.
\end{abstract}

Keywords: Remodeling, Myocardial infarction, Cardiac function, Nipradilol, Left ventricular diastolic volume

In experimental (1) and clinical (2) studies, it has been shown that the left ventricular (LV) cavity dilates progressively following acute myocardial infarction (MI), namely, $L V$ remodeling. $L V$ remodeling is a major risk factor for mortality and morbidity after MI (3). It has been reported that angiotensin-converting enzyme inhibitors such as captopril suppress remodeling in experimental (4) and clinical (5) studies. Furthermore, recent studies have demonstrated that angiotensin II type 1 receptor blockers (6) and nitrates $(7,8)$ may attenuate LV remodeling in some animal models of MI. The reduction of $\mathrm{LV}$ remodeling by these three different types of drugs is believed to result from LV unloading due to their vasodilation.

$\beta$-Adrenergic blockers are often used in the treatment of patients with acute $\mathrm{MI}$ and have been shown to reduce morbidity and mortality at the acute and chronic stage of MI, presumably by preventing myocardial ischemia in the jeopardized myocardium and arrhythmia $(9,10)$. However, previous studies in rats have suggested that propranolol may promote LV dilation following MI (11, $12)$, which may adversely affect $L V$ function.

Nipradilol (3,4-dihydro-8-(2-hydroxy-3-isopropylamino) propoxy-3-nitroxy-2H-1-benzopyran) is a $\beta$-blocker that has a vasodilating action partly mediated by the nitrate moiety of the chemical structure $(13,14)$, in addition to the non-selective $\beta$-adrenergic blocking action. Nipradilol, but not propranolol, has been demonstrated to increase venous compliance and show an LV unloading in clinical $(15,16)$ and animal (14) studies.

From these observations, we considered that nipradilol may reduce the LV remodeling through LV unloading. Therefore, we performed this study to determine whether chronic treatment of nipradilol favorably affects $\mathrm{LV}$ 
remodeling and cardiac performance following $\mathrm{MI}$ in rats.

\section{MATERIALS AND METHODS}

The rats used in this study were handled according to the animal welfare regulations of our institution, and the protocol was approved by the Animal Use Committee of the institution. These regulations are in accordance with the principles of animal use of the American Physiological Society.

\section{Experimental $M I$}

MI was produced in 16-week-old female Wistar rats $(n=150)$ by the previously described method (17). In brief, the rats were anesthetized with ether and a leftsided thoracotomy was performed. The heart was exteriorized and a coronary artery was ligated with a $5 / 0$ braided silk suture. The heart was returned to the chest cavity and the wound was rapidly closed. Two days after the ligation, the surviving rats were randomly divided into two groups: nipradilol- $(n=46)$ and vehicle- $(n=48)$ treated groups. Imposed oral administration of nipradilol (10 mg/ $\mathrm{kg}$, suspended in $2 \mathrm{ml} / \mathrm{kg}$ of $0.5 \%$ carboxymethylcellulose (CMC), once daily) or vehicle $(2 \mathrm{ml} / \mathrm{kg} /$ day of $0.5 \% \mathrm{CMC}$, once daily) to the respective treatment group began on the second day of MI production and continued for 3-4 months. The dose used in this study has been reported to lower arterial pressure in spontaneously hypertensive rats (approximately $10 \mathrm{mmHg}$ ) after single oral administration, which was associated with reduction of peripheral vascular resistance (13). In another set of experiments, age- and sex-matched Wistar rats $(n=9)$ were sham-operated and treated daily with the vehicle.

The rats were maintained under a room temperature of $23 \pm 2{ }^{\circ} \mathrm{C}$, a room humidity of $60 \pm 10 \%, 12$-hr light/dark cycle, and allowed food and water ad libitum.

\section{Measurements of hemodynamics}

On the day after the final administration, the rats were anesthetized lightly with pentobarbital sodium (30 $\mathrm{mg} / \mathrm{kg}$, i.p.). A micromanometer-tipped catheter transducer (CTC-047N; Nihon Kohden, Tokyo) was inserted into the right carotid artery, advanced into the aorta to measure aortic blood pressure, and then inserted into the LV cavity to measure LV pressure. The rate of change of LV pressure divided by simultaneous $\mathrm{LV}$ pressure $(\mathrm{dP} / \mathrm{dt} / \mathrm{P})$ was measured by a pressure processor $(\mathrm{EQ}$ 600-G, Nihon Kohden). Peak positive and negative $\mathrm{dP} / \mathrm{dt} / \mathrm{P},(+\mathrm{dP} / \mathrm{dt} / \mathrm{P})_{\max }$ and $(-\mathrm{dP} / \mathrm{dt} / \mathrm{P})_{\max }$, were used as indices of LV contractility and relaxation, respectively. A lead II electrocardiograph was recorded and the heart rate (HR) was measured. A thoracotomy was then per- formed and ventilation was maintained with a positive pressure respirator (Rodent Respirator 680; Harvard Apparatus, South Natick, MA, USA) at 60 strokes/min and a tidal volume of $1 \mathrm{ml} / 100 \mathrm{~g}$ body weight. An electromagnetic flow probe (FT-025T, Nihon Kohden) was placed around the ascending aorta to measure baseline cardiac output. We waited for at least $30 \mathrm{~min}$ before recording hemodynamic variables, by which time they had became stable. To assess the maximum output-generating capacity $\left(\mathrm{CI}_{\max }\right)$ of the heart, we measured maximal cardiac output by the previously described method (4). In brief, Tyrode's solution bubbled with $95 \% \mathrm{O}_{2}$ and $5 \%$ $\mathrm{CO}_{2}$ and maintained at $37^{\circ} \mathrm{C}$ was infused rapidly at the rate of $30.6 \mathrm{ml} / \mathrm{min}$ through the cannula inserted into the right jugular vein, to produce a rise in cardiac output to the maximal and plateau levels. We recorded mean ar-

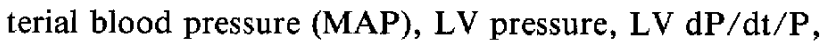
$\mathrm{HR}$ and cardiac output in each rat. The cardiac index (CI) was derived by normalizing the cardiac output by the body weight (in kilograms), and the systemic vascular resistance (SVR) before saline loading was calculated from the baseline cardiac output and MAP.

\section{Isolated LV pressure-volume relationships}

After the completion of all hemodynamic measurements, $1.0 \mathrm{ml}$ of $2 \mathrm{mM} \mathrm{KCl}$ was rapidly injected intravenously to arrest the heart in diastole. The $\mathrm{LV}$ pressurevolume relation was assessed by the previously described method (18). Briefly, the heart was removed and the right ventricle was incised. A double-lumen catheter, attached to a pressure transducer (Statham P50; Gould Instruments Co., Cleveland, OH, USA) and an infusion pump (A-2; Truth, Tokyo), was passed into the LV and tied with a ligature at the atrioventricular groove to isolate the LV from the left atrium. After gentle aspiration to reduce the pressure to about $-5 \mathrm{mmHg}$, saline was infused at $0.68 \mathrm{ml} / \mathrm{min}$ into the $\mathrm{LV}$, while $\mathrm{LV}$ pressure was continuously recorded until it reached $30 \mathrm{mmHg}$. The pressure-volume curves were generated over the pressure range of $0-30 \mathrm{mmHg}$. Ventricular volumes at $0,3,5,10,15,20,25$ and $30 \mathrm{mmHg}$ were calculated from the infusion rate and time. The volumes normalized to body weight were used for analysis. As a measure of the $L V$ cavity volume, the $L V$ end-diastolic volume index (LVEDVI) was estimated from the measured left ventricular end-diastolic pressure (LVEDP) and the LV pressure-volume curve in each heart, as described by Pfeffer et al. (4). In short, the LV volume was determined by finding the volume on the recorded postmortem pressure-volume curve that corresponded to the end-diastolic pressure obtained in the hemodynamic measurements in vivo. 


\section{$L V$ chamber stiffness}

The chamber stiffness constant, $\mathbf{K}_{\mathrm{c}}$, was determined as reported previously $(19,20)$. Pressure-volume curves at the LV pressure range above $3 \mathrm{mmHg}$ were fitted to the following exponential function:

$$
\mathrm{P}=\mathrm{b} \exp \left(\mathrm{K}_{\mathrm{c}} \mathrm{V}\right)+\mathrm{c} \quad \text { (for } 3 \leqq \mathrm{P} \leqq 30 \mathrm{mmHg} \text { ) }
$$

where $\mathrm{P}$ is the $\mathrm{LV}$ pressure and $\mathrm{V}$ is the ventricular volume index.

$\mathrm{K}_{0}$ at the pressure range of $3-30 \mathrm{mmHg}$ is the overall chamber stiffness constant. $K_{1}$ at the pressure range of 3-10 $\mathrm{mmHg} ; \mathrm{K}_{2}, 10-20 \mathrm{mmHg}$; and $\mathrm{K}_{3}, 20-30 \mathrm{mmHg}$ were calculated as the slope from the curvilinear relation in the respective pressure range according to the formula:

$$
\mathrm{dP} / \mathrm{dV}=\mathrm{K}_{\mathrm{c}} \mathrm{P} \quad(\text { for } \mathrm{c}=0-3) .
$$

\section{Infarct size measurement}

After assessment of the pressure volume curve, $10 \%$ formalin solution was infused into the LV until then the pressure achieved $20 \mathrm{mmHg}$, and then the heart was fixed with this pressure for more than $48 \mathrm{hr}$. The LV was then weighed, embedded in paraffin, and cut into serial $4-\mu \mathrm{m}$ sections at 2-mm intervals from the apex to the base. These specimens were stained with Azan and the infarct size was determined in each animal by using the techniques described earlier (4). In short, the perimeter of the scar and that of the non-infarcted muscle for both the endocardial and epicardial surface of each section were measured three times with a microcomputer-controlled curvimeter (S-type; Uchida Yoko, Tokyo) and averaged. The circumferential lengths of the scar at the endocardial and epicardial surfaces in all histological sections were numerically summed separately. The ratio of the sum of the scar circumferences to the sum of the surface circumferences defined the infarct size.

\section{Data analyses}

The MI size is known to influence the magnitude of LV cavity volume expansion (21). To assess the effects of nipradilol on LV remodeling, the comparison of LV volumes was made between rats with similar MI size $(10 \%-40 \%)$ of the vehicle- and the nipradilol-treated groups. By the previously reported criteria of MI size classification (4), $10-40 \%$ of MI was classified into "small" and "medium" groups and $>40 \%$ "large" and "extensive large". On the basis of this, we used the rats with $10-40 \%$ of MI in this study. In rats with infarcts greater than $40 \%$, however, we could not obtain a sufficient number of animals to compare the variables between the vehicle- and nipradilol-treated rats.

All values are expressed as means \pm S.E.M. Analysis of variance (ANOVA) was applied to compare mean values among the groups. When ANOVA showed statistical significance by the $F$-test, intergroup comparisons among the sham-operated, the vehicle-treated and the nipradiloltreated groups were made by Tukey multiple comparison test. A value of $\mathrm{P}<0.05$ was considered to be statistically significant.

\section{RESULTS}

Table 1 shows the number of animals, body weight (BW), LV weight per $100 \mathrm{~g}$ of body weight ( $\mathrm{LV} /$ body weight) and the treatment period. The treatment period did not differ among the sham-operated, the vehicletreated and the nipradilol-treated rats. BW of the shamoperated and the nipradilol-treated rats were significantly greater than that of the vehicle-treated rats. Values of the $\mathrm{LV} /$ body weight of the vehicle- and the nipradilol-treated rats were significantly greater than that of the sham-operated rats. The mean infarct size of the nipradilol group used in this study was slightly but significantly greater than that of the vehicle group.

Table 2 shows the baseline hemodynamics in these three groups. Among the three groups, there were no differences in MAP and HR. The CI in the vehicle and the nipradilol groups were significantly lower than that in the sham group. LVEDP in the vehicle-treated rats with MI was significantly greater than that in the sham-operated

\begin{tabular}{|c|c|c|c|c|c|}
\hline Group & $\mathrm{n}$ & $\begin{array}{l}\text { BW } \\
(\mathrm{g})\end{array}$ & $\operatorname{Inf}_{(\%)}$ & $\begin{array}{l}\text { LV/body weight } \\
(\mathrm{mg} / 100 \mathrm{~g})\end{array}$ & $\underset{\text { (day) }}{\text { Treatment period }}$ \\
\hline Sham-operated & 9 & $343 \pm 15$ & $0.0 \pm 0.0$ & $1.69 \pm 0.14$ & $95=4$ \\
\hline \multicolumn{6}{|l|}{ Infarcted } \\
\hline Vehicle-treated & 22 & $296 \pm 3^{* *}$ & $24.5 \pm 1.1^{* *}$ & $2.37 \pm 0.05^{* *}$ & $95 \pm 2$ \\
\hline Nipradilol-treated & 20 & $312 \pm 3^{*}$ & $30.0 \pm 1.2^{* * \ldots+1}$ & $2.21 \pm 0.03^{*}$ & $100 \pm 3$ \\
\hline
\end{tabular}

Table 1. Baseline parameters in the sham-operated, vehicle- and nipradilol-treated rats

$\mathrm{n}$, Number of animals; BW, body weight; Inf, myocardial infarct size; LV/body weight, left ventricular weight per body weight ratio. ${ }^{*} \mathrm{P}<0.05,{ }^{* *} \mathrm{P}<0.01$ vs the sham-operated rats without myocardial infarction. ${ }^{5} \mathrm{P}<0.05$, ${ }^{\# \#} \mathbf{P}<0.01$ vs the vehicle-treated rats with myocardial infarction. 
Table 2. Baseline hemodynamics in the sham-operated, vehicle- and nipradilol-treated rats

\begin{tabular}{|c|c|c|c|c|c|c|c|c|}
\hline Group & $\mathrm{n}$ & $\underset{(\mathrm{mmHg})}{\mathrm{MAP}}$ & $\underset{\text { (beats/min) }}{\text { HR }}$ & $\underset{(\mathrm{ml} / \mathrm{min} / \mathrm{kg})}{\mathrm{CI}}$ & $\begin{array}{l}\text { LVEDP } \\
\text { (mmHg) }\end{array}$ & $\left(+\underset{\left(\sec ^{-1}\right)}{\mathrm{dP} / \mathrm{dt} / \mathrm{P})_{\max }}\right.$ & $\underset{\left(\mathrm{sec}^{-1}\right)}{(-\mathrm{dP} / \mathrm{dt} / \mathrm{P})_{\max }}$ & $\begin{array}{c}\text { SVR } \\
\left(\times 10^{4} \mathrm{dyn} / \mathrm{sec} / \mathrm{cm}^{5}\right)\end{array}$ \\
\hline Sham-operated & 9 & $104 \pm 5$ & $407 \pm 16$ & $163.9 \pm 14.1$ & $2.8 \pm 0.7$ & $286.1 \pm 22.5$ & $233.6 \pm 37.7$ & $5.37 \pm 0.48$ \\
\hline \multicolumn{9}{|l|}{ Infarcted } \\
\hline Vehicle-treated & 22 & $93 \pm 3$ & $421 \pm 9$ & $114.9 \pm 6.6^{* *}$ & $11.8 \pm 1.7^{* *}$ & $182.1 \pm 16.5^{* *}$ & $166.7 \pm 15.9^{*}$ & $7.13 \pm 0.64^{*}$ \\
\hline Nipradilol-treated & 20 & $94 \pm 4$ & $409 \pm 12$ & $131.3 \pm 8.1^{*}$ & $3.8 \pm 0.6^{\# \#}$ & $234.3 \pm 10.9^{\#}$ & $207.5 \pm 10.9$ & $6.29 \pm 0.51$ \\
\hline
\end{tabular}

n, Number of animals; MAP, mean arterial blood pressure; HR, heart rate; CI, cardiac index; LVEDP, left ventricular end-diastolic pressure; $(+\mathrm{dP} / \mathrm{dt} / \mathrm{P})_{\max }$, maximum rate of rise of left ventricular pressure normalized by simultaneous left ventricular pressure; $(-\mathrm{dP} / \mathrm{dt} / \mathrm{P})_{\max }$, maximum rate of decline of left ventricular pressure normalized by simultaneous left ventricular pressure; SVR, systemic vascular resistance. ${ }^{*} \mathrm{P}<0.05,{ }^{* *} \mathrm{P}<0.01$ vs the sham-operated rats without myocardial infarction, ${ }^{\sharp} \mathrm{P}<0.05,{ }^{\# /} \mathrm{P}<0.01$ vs the vehicle-treated rats with myocardial infarction.

rats. Of the rats with MI, LVEDP in the nipradilol group was significantly smaller than that in the vehicle group. The SVR in the vehicle group was greater than that in the sham group $(\mathrm{P}<0.01) .(+\mathrm{dP} / \mathrm{dt} / \mathrm{P})_{\max }$ and $(-\mathrm{dP} / \mathrm{dt} / \mathrm{P})_{\max }$ in the vehicle group with MI were significantly smaller than those in the sham-operated group. In the nipradilol group, $(+\mathrm{dP} / \mathrm{dt} / \mathrm{P})_{\max }$ was significantly greater than in the vehicle group.

The LV pressure-volume relation obtained by passive volume loading is shown in Fig. 1. The curve of pressurevolume relation in the vehicle-treated rats with MI was significantly shifted to the right from that in the shamoperated rats without MI. The curve of the nipradiloltreated rats with MI was rightward-shifted from that of the sham-operated rats without MI and leftward-shifted from that of the vehicle-treated rats with MI.

Table 3 shows the LV chamber stiffness constants calculated from the curve-analysis of the LV pressurevolume curve. The stiffness constants in all of the pressure ranges in the vehicle group were significantly smaller than that in the sham-operated group. Of the infarcted rats, $\mathrm{K}_{3}$ of the nipradilol-treated group was significantly greater than that in the vehicle-treated group and the other stiffness constants of the nipradilol group tended to be greater than those of the vehicle group.

LVEDVI, a measure of LV cavity volume, in each group is shown in Fig. 2. LVEDVI in the vehicle-treated rats with MI was significantly greater than that in the

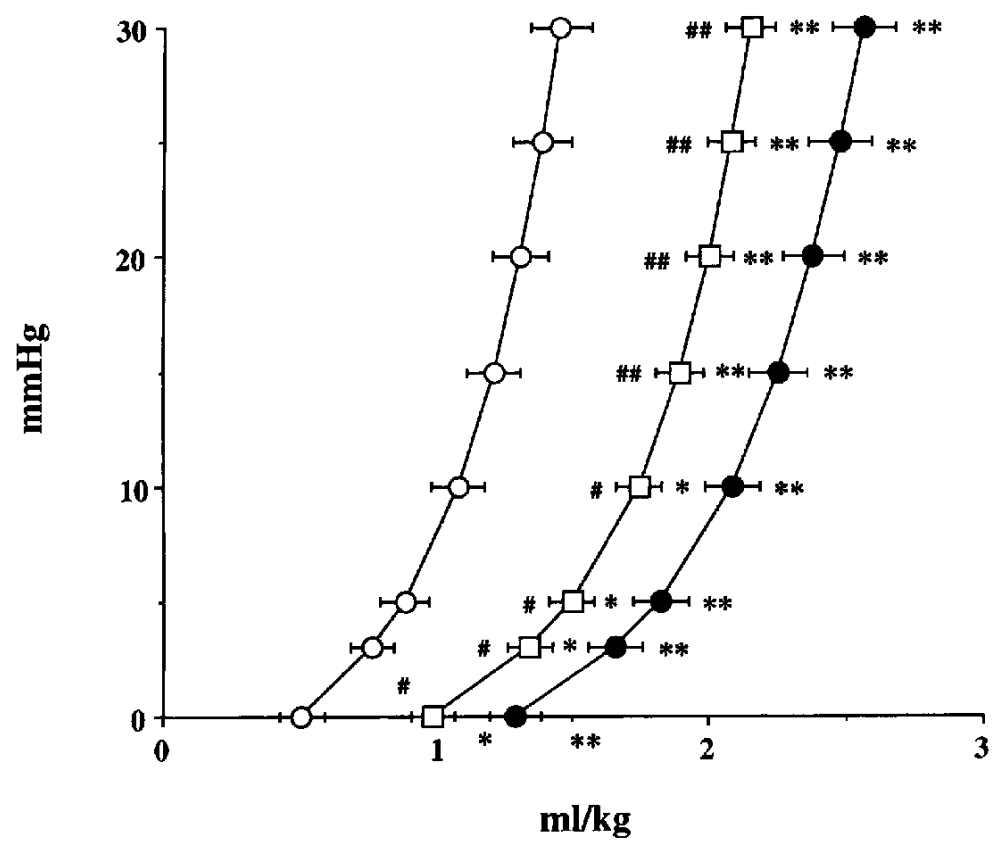

Fig. 1. Left ventricular pressure-volume (per kg) relationship of the sham-operated $(O, n=9)$, the vehicle- $(0, n=22)$ and the nipradilol-treated $\left(\square, \mathrm{n}=20\right.$ ) rats. Each point and horizontal bar indicate the mean \pm S.E.M. ${ }^{*} \mathrm{P}<0.05,{ }^{* *} \mathrm{P}<0.01$ vs the sham-operated rats without myocardial infarction; ${ }^{\# P}<0.05,{ }^{\# /} \mathbf{P}<0.01$ vs the vehicle-treated rats with myocardial infarction. 
Table 3. Left ventricular chamber stiffness constant in the sham-operated, vehicle- and nipradilol-treated rats

\begin{tabular}{lccccc}
\hline Group & $\mathbf{n}$ & $\mathrm{K}_{0}$ & $\mathrm{~K}_{1}$ & $\mathrm{~K}_{2}$ & $\mathbf{K}_{3}$ \\
\hline Sham-operated & 9 & $3.705 \pm 0.264$ & $3.970 \pm 0.237$ & $3.565 \pm 0.317$ & $3.477 \pm 0.315$ \\
Infarcted & & & & & \\
$\quad$ Vehicle-treated & 22 & $2.708 \pm 0.152^{* *}$ & $3.044 \pm 0.189^{* *}$ & $2.546 \pm 0.142^{* *}$ & $2.360 \pm 0.128^{* *}$ \\
$\quad$ Nipradilol-treated & 20 & $2.922 \pm 0.113^{* *}$ & $3.121 \pm 0.144^{*}$ & $2.803 \pm 0.104$ & $2.777 \pm 0.099^{*}$ \\
\hline
\end{tabular}

$n$, Number of animals; $K_{0-3}$, Left ventricular chamber stiffness constants. Respective pressure ranges were: $K_{0}, 3-30$ $\mathrm{mmHg} ; \mathrm{K}_{1}, 3-10 \mathrm{mmHg} ; \mathrm{K}_{2}, 10-20 \mathrm{mmHg} ; \mathrm{K}_{3}, 20-30 \mathrm{mmHg} .{ }^{*} \mathrm{P}<0.05,{ }^{*} \mathrm{P}<0.01$ vs the sham-operated rats without myocardial infarction, ${ }^{*} \mathrm{P}<0.05$ vs the vehicle-treated rats with myocardial infarction.

sham-operated rats without MI. LVEDVI in the nipradilol group was significantly smaller than that in the vehicle group.

The $\mathrm{CI}_{\max }$, an index of the capacity of maximum cardiac output-generation, in the vehicle group with MI was significantly smaller than that in the sham-operated rats. $\mathrm{CI}_{\max }$ in the nipradilol group was significantly greater than that in the vehicle group and did not differ from that in the sham-operated group (Fig. 3).

\section{DISCUSSION}

The purpose of this investigation was to examine the chronic effects of a $\beta$-adrenergic blocker with vasodilating action, nipradilol, on LV dynamics and compliance in rats with MI. The results indicate that LV cavity dilation following MI was reduced by chronic therapy with nipradilol; this effect was associated with the improvement in $\mathrm{LV}$ cardiac performance.

The effects of chronic MI on cardiac and hemodynamic function can be assessed by comparing the findings in the vehicle-treated rats with $\mathrm{MI}$ and those in the sham-operated rats without MI. The rightward shift of the LV pressure-volume curve and the greater LVEDVI in the rats with $\mathrm{MI}$ in comparison with the rats without MI suggest that 3-4 months MI caused LV remodeling. The LVEDVI in the MI rats was more than two times greater than that in the non-infarcted rats, indicating that LV cavity dilation occurred in not only infarcted but non-infarcted regions of the heart. In analysis of the pressure-

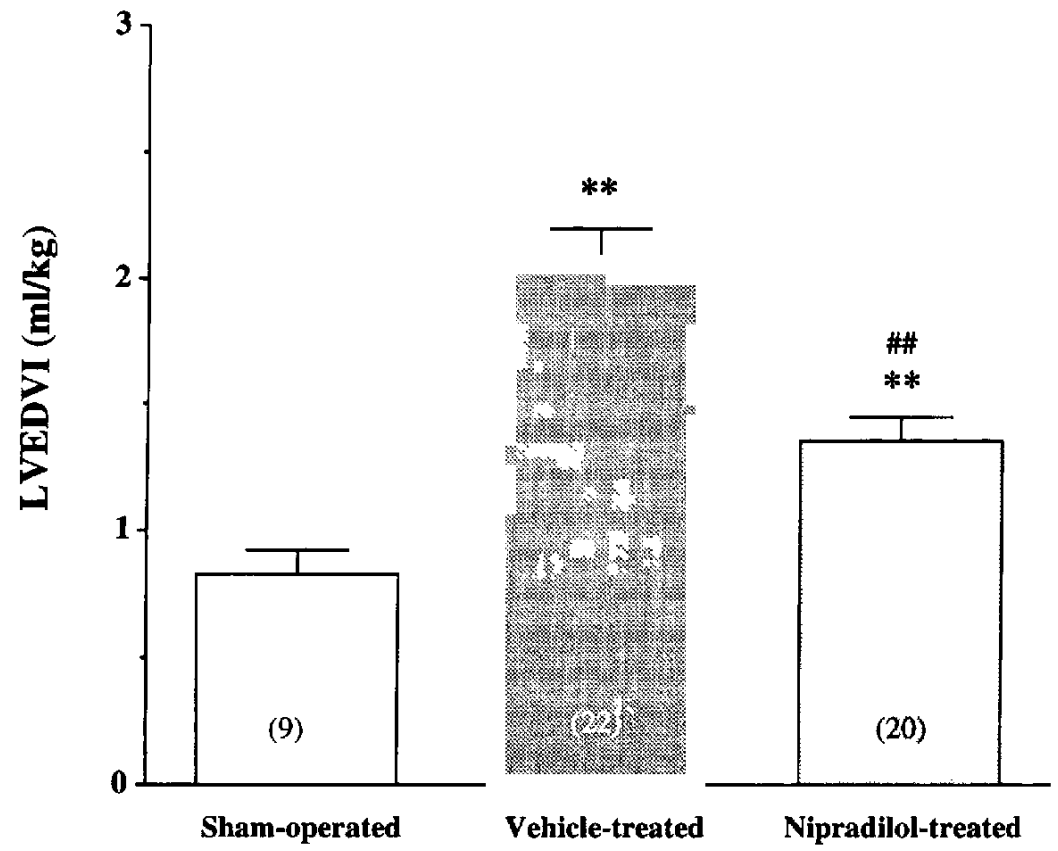

Fig. 2. Left ventricular end-diastolic volume index of the sham-operated, the vehicle- and the nipradilol-treated rats. LVEDVI, left ventricular end-diastolic volume index. Values indicate the mean \pm S.E.M. ${ }^{* *} \mathrm{P}<0.01$ vs the sham-operated rats without myocardial infarction, ${ }^{* \#} \mathrm{P}<0.01$ vs the vehicle-treated rats with myocardial infarction. ( ): Number of animals used for determination of left ventricular end-diastolic volume index. 


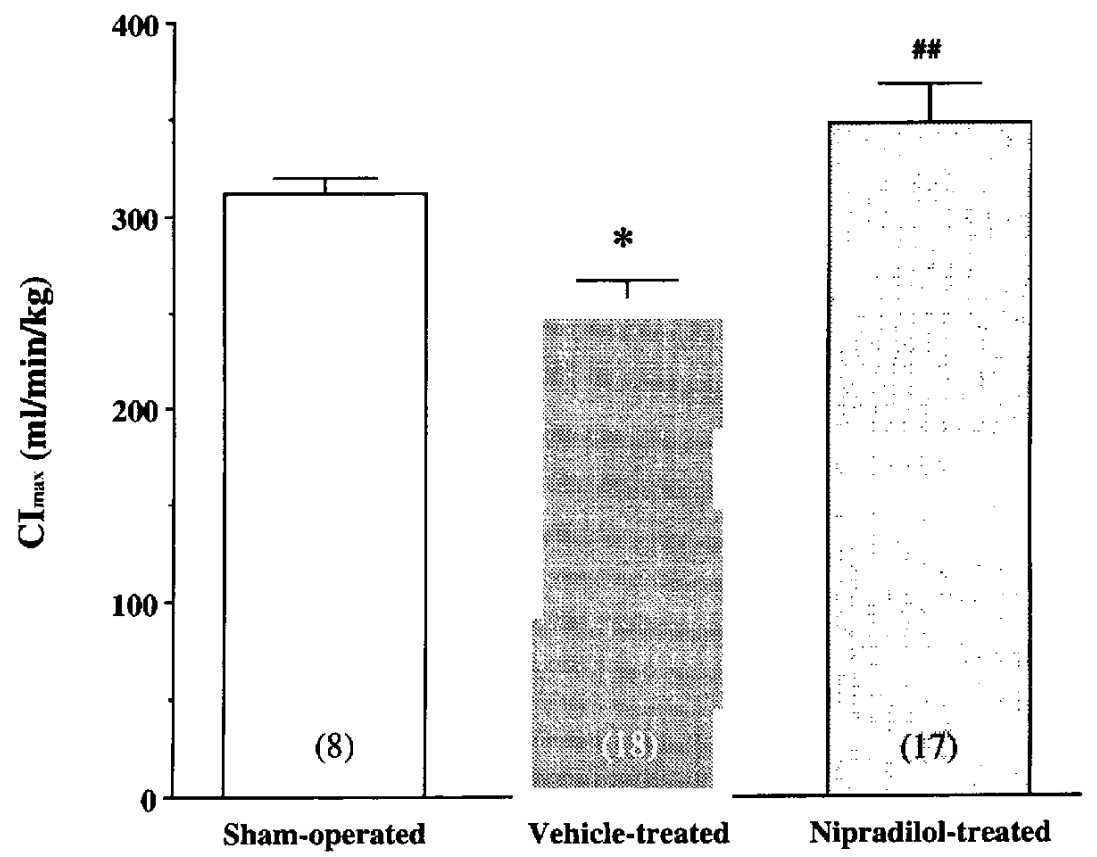

Fig. 3. Maximum cardiac index achieved by volume loading by saline infusion in the sham-operated, the vehicle- and the nipradilol-treated rats. $\mathrm{CI}_{\max }$, maximum cardiac index. Values indicate the mean \pm S.E.M. ${ }^{*} \mathrm{P}<0.05$ vs the sham-operated rats without myocardial infarction, ${ }^{\#} \mathrm{P}<0.01$ vs the vehicle-treated rats with myocardial infarction. ( ): Number of animals used for determination of maximum cardiac index.

volume curves, the smaller $\mathrm{LV}$ stiffness constants observed in the MI rats means that there is a smaller increase in LV pressure for any given volume during saline loading, which may also reflect an eccentric LV chamber dilation by MI. Of the baseline hemodynamics, LVEDP in the MI animals was higher than that in the non-infarcted animals, which indicates that $L V$ preload increased after MI. The smaller values of $\mathrm{CI}, \mathrm{CI}_{\max }, \mathrm{LV}(+\mathrm{dP} / \mathrm{dt} / \mathrm{P})_{\max }$ and $(-\mathrm{dP} / \mathrm{dt} / \mathrm{P})_{\max }$ in the rats with MI suggest that MI caused cardiac dysfunction and impaired LV contractility and relaxation.

The effects of nipradilol on $\mathrm{LV}$ remodeling and hemodynamics may be assessed by comparing the findings between the vehicle- and nipradilol-treated rats with MI. In a previous study (13) using hypertensive rats, nipradilol given in a dose of $10 \mathrm{mg} / \mathrm{kg}$ has been reported to show a hypotensive effect after a single oral administration, which was associated with reductions of $H R$ and SVR. Thus, we used the dose assumed to be enough to show such cardiovascular effects in this study. However, MAP and HR in the nipradilol-treated rats did not differ from those in the vehicle-treated rats. These hemodynamic discrepancies might depend on the disappearance of significant cardiovascular effects of nipradilol because the hemodynamic measurements were performed more than $24 \mathrm{hr}$ after the last administration and/or on difference of the experimental conditions, i.e., the lineage difference between hypertensive and normotensive rats. Nipradilol shifted the $\mathrm{LV}$ pressure-volume curve to the left and reduced LVEDVI. Several factors are known to influence LV cavity volume after MI, including the location of the ligature in the coronary artery, the onset of the drug treatment, the time after MI $(1,2)$ and the infarct size (21). Among these factors, the ligature location and the onset of treatment were the same in the vehicle- and nipradilol-treated animals. The time after MI may not be a factor either in this study because the treatment days did not differ between these two groups. The difference in the degree of $L V$ dilation was unlikely to be related to such non-specific factors. LV cavity enlargement after MI has been reported to increase in proportion to the size of MI (21). In the present study, the mean size of MI in the nipradilol rats was slightly but significantly greater than that in the vehicle rats. Despite the larger MI size, the nipradilol-treated rats had a significantly smaller LV cavity volume than the vehicle-treated rats. These observations suggest that nipradilol reduced the LV remodeling following MI. The greater stiffness constants in the nipradilol rats may also reflect the reduction of $\mathrm{LV}$ chamber dilation by nipradilol. Of the baseline hemodynamics, the cardiac contractility was improved by nipradilol because $(+\mathrm{dP} / \mathrm{dt} / \mathrm{P})_{\max }$ in the nipradilol rats was greater than that in the vehicle rats. Nipradilol increased $\mathrm{CI}_{\max }$ and decreased LVEDP, suggesting that 
chronic therapy with nipradilol improves the cardiac dysfunction and reduces the preload.

Several reports, investigating the effects of propranolol on the MI-induced LV remodeling in rats, have demonstrated that propranolol facilitated or did not reduce the $L V$ remodeling after $M I(11,12)$. These reports suggest that the beneficial effects of nipradilol on $\mathrm{LV}$ remodeling following $\mathrm{MI}$ in rats did not result from its $\beta$-blocking action. The mechanisms by which nipradilol reduced LV remodeling after $\mathrm{MI}$ in Wistar rats are not known from our study. However, it has been demonstrated that angiotensin-converting enzyme inhibitors (4) and angiotensin II type 1 receptor blocker (6) reduce LV cavity enlargement after MI through reduction of preload and afterload and/or through suppression of the reninangiotensin-aldosterone system. The former leads to $\mathrm{LV}$ unloading, and the latter system has been shown to play an important role in the development of reactive hypertrophy and fibrosis accompanied by $\mathrm{LV}$ remodeling (22). Hirai et al. (23) have reported that the long-term administration of nitrates may also reduce $\mathrm{LV}$ remodeling in a canine model of MI and suggested that the decreases of preload and afterload and/or the increase of collateral blood flow contribute to its reduction of $\mathrm{LV}$ remodeling. Raya et al. (24) have demonstrated the importance of reduction of preload in inhibition of $L V$ remodeling since hydralazine, a reducer of afterload, did not alter LV remodeling in their study. Thus, the decrease in the preload appears to be an important mechanism to reduce the LV remodeling. Moreover, LV wall stress is believed to be causally related to progressive LV dilation following MI. Histological studies suggested that the increased wall stress by the increased $L V$ radius due to the wall thinning after MI produces progressive cell elongation (25) and side-to-side cell slippage (26) of the non-infarcted myocardium. The explanation for the mechanism of $\mathrm{LV}$ remodeling is provided by these histological changes in the non-infarcted region of the MI heart due to increased wall stress. These also suggest that the alleviation of $\mathrm{LV}$ wall stress is important in the therapy of the remodeling after MI. In the present study, nipradilol failed to decrease SVR and alter LV afterload. On the other hand, preload was reduced by nipradilol. Nipradilol has been reported to produce venodilation and increase venous compliance in experimental (14) and clinical $(15,16)$ studies, which may contribute to the preload reduction observed in this study. A decrease in preload can lead to both $\mathrm{LV}$ unloading and a decline in wall tension, which are suggested to be related to the progression of $\mathrm{LV}$ remodeling after MI. Thus, it is conceivable that the preload reduction by nipradilol attenuated the LV loading condition, relieved geometrical stress in the LV wall, and reduced the $L V$ remodeling following $M I$.
In conclusion, chronic nipradilol treatment for 3-4 months after $\mathrm{MI}$ attenuated $\mathrm{LV}$ remodeling and improved cardiac function. It was considered that the preload reduction by nipradilol may contribute to the beneficial effects on LV remodeling after MI.

\section{Acknowledgment}

We gratefully acknowledge Ms. Hiroe Asami for her helpful technical assistance.

\section{REFERENCES}

1 Pfeffer JM, Pfeffer MA, Fletcher PJ and Braunwald E: Progressive ventricular remodeling in rats with myocardial infarction. Am J Physiol 261, H1406-H1414 (1991)

2 Vaughan DE and Pfeffer MA: Post-myocardial infarction ventricular remodeling: Animal and human studies. Cardiovasc Drug Ther 8, 453-460 (1994)

3 White HD, Norris RM, Brown MA, Brandt PWT, Whitlock RHL and Wild CJ: Left ventricular end-systolic volume as the major determinant of survival after recovery from myocardial infarction. Circulation 76, 44-51 (1987)

4 Pfeffer JM, Pfeffer MA and Braunwald E: Influence of chronic captopril therapy on the infarcted left ventricle of the rat. Circ Res 57, 84-95 (1985)

5 Pfeffer MA, Lamas GA and Vaughan DE: Effect of captopril on progressive ventricular dilation after anterior myocardial infarction. N Engl J Med 319, 80-86 (1988)

6 Nishikimi $T$, Yamagishi $H$, Takeuchi $K$ and Takeda $T$ : An angiotensin II receptor antagonist attenuates left ventricular dilation after myocardial infarction in the hypertensive rat. Cardiovasc Res 29, 856-861 (1995)

7 McDonald KM, Francis GS, Matthews J, Hunter D and Cohn JN: Long-term oral nitrate therapy prevents chronic ventricular remodeling in the dog. J Am Coll Cardiol 21, 514-522 (1993)

8 Jugdutt BI and Khan MI: Effect of prolonged nitrate therapy on left ventricular remodeling after canine acute myocardial infarction. Circulation 89, 2297-2307 (1994)

9 Yusuf S, Peto R, Lewis J, Collins R and Sleight P: Beta blockade during and after myocardial infarction: an overview of the randomized trials. Prog Cardiovasc Dis 27, 335-371 (1985)

10 The Beta-Blocker Pooling Project Research Group: The BetaBlocker Pooling Project (BBPP): subgroup findings from randomized trials in postinfarction patients. Eur Heart J 9, 8-16 (1988)

11 Fishbein MC, Lei L-Q and Rubin SA: Long-term propranolol administration alters myocyte and ventricular geometry in rats hearts with and without infarction. Circulation 78, 369-375 (1988)

12 Gay RG, Raya TE and Goldman S: Chronic propranolol treatment promotes left ventricular dilation without altering systolic function after large myocardial infarction in rats. $\mathbf{J}$ Cardiovasc Pharmacol 16, 529-536 (1990)

13 Uchida $Y$, Nakamura M, Shimizu S, Shirasawa $Y$ and Fujii M: Vasoactive and $\hat{\beta}$-adrenoceptor blocking properties of 3,4-dihydro-8(2-hydroxy-3-isopropylamino)propoxy-3-nitroxy-2H-1benzopyran (K-351), a new antihypertensive agent. Arch Int Pharmacodyn Ther 262, 132-149 (1983)

14 Shirasawa Y, Fujii M and Nakamura M: Venodilating action of 
nipradilol (K-351) in the pithed rat pretreated with dihydroergotamine. Jpn J Pharmacol 39, 77-82 (1985)

15 Ebihara A, Kondo K and Ohashi K: Pharmacodynamic and pharmacological effects of nipradilol (K-351) in healthy volunteers. - comparison with propranolol - . Jpn J Clin Pharmacol Ther 17, 391 - 401 (1986) (Abstr in English)

16 Nakanishi $T$, Nishimura $M$, Kubota $S$ and Hirabayashi $M$ : Effects of nipradilol on 24-hour blood pressure in patients with essential hypertension. Curr Ther Res 48, 198-205 (1990) (Abstr in English)

17 Selye H, Bajusz E, Grasso S and Mendell P: Simple techniques for the surgical occlusion of coronary vessels in the rat. Angiology 11, 398-407 (1960)

18 Fletcher PJ, Pfeffer JM, Pfeffer MA and Braunwald E: Left ventricular diastolic pressure-volume relations in rats with healed myocardial infarction. Effects on systolic function. Circ Res 49, 618-626 (1981)

19 Gaasch WH, Levine HJ, Quinones MA and Alexander JK: Left ventricular compliance: Mechanisms and clinical implications. Am J Cardiol 38, 645-653 (1976)

20 Mirsky I: Assessment of passive elastic stiffness of cardiac muscle: mathematical concepts, physiologic and clinical considerations, directions of future research. Prog Cardiovasc Dis 18,
$277-308$ (1976)

21 McKay RG, Pfeffer MA, Pasternak RC, Markis JE, Come PC, Nakao S, Alderman, JD, Ferguson JJ, Safian RD and Grossman W: Left ventricular remodeling after myocardial infarction: a corollary to infarct expansion. Circulation 74, 693-702 (1986)

22 Weber KT and Brilla CG: Pathological hypertrophy and cardiac interstitium: fibrosis and renin-angiotensin-aldosterone system. Circulation 83, 1849-1865 (1991)

23 Hirai T, Fujita M, Nakajima H, Asanoi H, Yamanishi K, Ohno A and Sasayama S: Importance of collateral circulation for prevention of ventricular aneurysm formation in acute myocardial infarction. Circulation 79, 791-796 (1989)

24 Raya TH, Gay RG, Aguirre M and Goldman S: Importance of venodilation in prevention of left ventricular dilation after chronic large myocardial infarction in rats: a comparison of captopril and hydralazine. Circ Res 64, 330-337 (1989)

25 Olivetti G, Capasso JM, Meggs LG and Sonnenblick EH: Cellular basis of chronic ventricular remodeling after myocardial infarction in rats. Circ Res 68, 856-869 (1991)

26 Weissman HF, Bush DE, Mannist JA, Weisfeldt ML and Healy B: Cellular mechanisms of myocardial infarct expansion. Circulation 76, 186-201 (1988) 